\title{
Envolvimento Paterno aos 24 meses de Vida da Criança
}

\author{
Marília Reginato Gabriel ${ }^{1}$ \\ Rodrigo Gabbi Polli \\ Luísa Fochesato Dall'Agnol \\ Universidade Federal do Rio Grande do Sul \\ Jonathan Tudge \\ University of North Carolina at Greensboro \\ Cesar Augusto Piccinini \\ Universidade Federal do Rio Grande do Sul
}

\begin{abstract}
RESUMO - O estudo investigou o envolvimento paterno de 27 pais adultos que tinham um filho/a com 24 meses. As respostas dos pais foram examinadas através de análise de conteúdo, com base em três dimensões: interação, disponibilidade e responsabilidade. Os resultados revelaram que os pais se relacionavam com o filho conforme as necessidades e capacidades da criança, entre elas a de mais autonomia. Os pais relataram que se envolviam em atividades de cuidado, sobretudo auxiliando o filho a dar conta de suas demandas. Também destacaram que interagiam e estavam disponíveis para o filho e revelaram preocupações sobre ele. Entretanto, a participação do pai foi percebida como menor quando comparada à da mãe, mesmo quando o pai compartilhava os cuidados e as responsabilidades.
\end{abstract}

Palavras-chave: envolvimento paterno, relações pais-criança, paternidade

\section{Fathers' Involvement with their 24-month-old Children}

\begin{abstract}
This study investigated father involvement at 24 months of a child's life. Twenty seven fathers, aged 19 to 40, were interviewed. The fathers' answers were analyzed using content analysis, based on three dimensions: interaction, availability, and responsibility. The results indicated that the fathers interacted with the children according to the specific needs and capabilities of their 24-month-olds, at a stage when they become more autonomous. The fathers reported that they were involved in care activities, especially helping the children to deal with their own demands. At the same time, the fathers were involved by interacting, being available and showing concern for their children. Nevertheless, the fathers' participation was noticed as lower when compared to that of the mothers, even when the father shared care and responsibility.
\end{abstract}

Keywords: father involvement, parent child relations, paternity

Diversos autores têm destacado a importância do envolvimento do pai para o desenvolvimento infantil (Veneziano, 2003). Por exemplo, estudos apontam que a participação do pai implica melhores índices de saúde mental, competências sociais (Flouri \& Buchanan, 2003), regulação de emoções e empatia (Matthey \& Barnett, 1999). Além disso, a participação do pai na vida do filho também parece influenciar o desenvolvimento cognitivo (Flouri \& Buchanan, 2003; Matthey \& Barnett, 1999), motor e social da criança (Manfroi, Macarini, \& Vieira, 2011) e contribui para um apego seguro (Brown, Mangelsdorf, \& Neff, 2012; Fuertes, Faria, Breeghly, \& Santos, 2016). Nesse sentido, torna-se relevante a investigação sobre o envolvimento paterno com o seu filho, especialmente nos primeiros anos de vida da criança, não só pela importância para o desenvolvimento infantil, mas para a própria paternidade.

Entre os diversos conceitos usados nas investigações sobre a paternidade, destaca-se, no presente estudo, o de envolvimento paterno proposto por Lamb, Pleck, Charnov e Levine (1985), o qual tem sido utilizado em muitas pesquisas

1 Endereço para correspondência: Rua Ramiro Barcelos, 2600, Térreo, Porto Alegre, RS, Brasil. CEP: 90.035-003.E-mail: gabrielmarilia@ yahoo.com.br sobre o tema realizadas em diversos contextos e em diferentes fases do ciclo vital (Castoldi, Gonçalves, \& Lopes, 2014; Piccinini, Silva, Gonçalves, Lopes, \& Tudge, 2004, 2012; Saleh \& Hilton; 2011). Três dimensões compõem o conceito de envolvimento paterno (Lamb et al., 1985): interação, disponibilidade e responsabilidade. A primeira dimensão refere-se ao contato direto do pai com seu filho, por meio do cuidado e de atividades compartilhadas. A segunda, disponibilidade, refere-se à acessibilidade física e psicológica que oportuniza a interação com a criança, o que sugere, mas não requer necessariamente, uma interação direta. Por fim, responsabilidade diz respeito ao papel do pai de garantir que a criança seja cuidada e que os recursos estejam disponíveis para ela. Para os autores, a responsabilidade também incluiria ansiedades, preocupações e planejamentos que fazem parte da parentalidade.

Vários aspectos do conceito de envolvimento paterno se assemelham ao conceito de prática da parentalidade, proposto mais recentemente por Houzel (2004), que se constitui em um dos três eixos que definem as funções parentais: exercício, experiência e prática. A prática diz respeito às 
tarefas cotidianas que os pais ${ }^{1}$ e mães devem realizar com seu filho, sendo que ambos têm seu papel a desempenhar nessas tarefas. $\mathrm{O}$ autor enfatiza que as tarefas englobam não só o cuidado físico, mas também os cuidados psíquicos da criança. Já a experiência é a vivência subjetiva do fato de vir a ser pai ou mãe e de preencher papéis parentais. Quanto ao exercício, este se relaciona a questões jurídicas, ao parentesco e à filiação, tendo como função organizar os indivíduos nos seus laços de parentesco, seus direitos e deveres. Essas últimas duas categorias não foram destacadas por Lamb et al. (1985) e tampouco serão abordadas no presente estudo, que se deterá nas dimensões do conceito de envolvimento paterno.

$\mathrm{O}$ envolvimento paterno tem sido estudado desde a gestação e os primeiros anos de vida em contextos típicos de desenvolvimento (Castoldi, 2002; Castoldi et al., 2014; Piccinini et al., 2004; Tudge, 2008), bem como de desenvolvimento atípico ou em contextos adversos, como pais que não moram com os filhos (Silva \& Piccinini, 2004), pais que casam ou coabitam após a notícia da gravidez (Hohmann-Marriott, 2011), situação de desemprego paterno (Souza, 2008), depressão pós-parto (Silva \& Piccinini, 2009), filhos com Síndrome de Down (Henn \& Piccinini, 2010) e portadores de Transtorno de Desenvolvimento (Yoshihara, 2008). Por exemplo, o estudo de Silva e Piccinini (2009) revelou que os pais investigados no contexto da depressão pós-parto da esposa se mostravam presentes e ativos ao cuidar dos filhos, auxiliando a esposa em tarefas domésticas. No entanto, havia certa dificuldade em apoiar emocionalmente as mães, assim como em disciplinar os filhos. Já no contexto da Síndrome de Down (Henn \& Piccinini, 2010), os pais também se mostraram ativamente envolvidos no cuidado com os filhos, embora o trabalho do pai aparecesse como limitador da sua atenção. Por vezes, o envolvimento paterno em situações de desenvolvimento atípico tende a ser maior do que em situações de desenvolvimento típico (Yoshihara, 2008).

Com relação aos estudos que se voltaram ao desenvolvimento típico, no período da gestação, o estudo de Piccinini et al. (2004), envolvendo entrevistas com 35 pais de Porto Alegre, revelou que o pai procurava se envolver com o bebê por meio de acompanhamento a ecografias e consultas, além de oferecer apoio emocional à mãe do bebê, estando disponível, conversando e tranquilizando a companheira. Ainda na gravidez, o pai interagia com o filho através da busca por contato ou da reação às manifestações do bebê no útero, atribuindo ao bebê características físicas e emocionais. As preocupações do pai também foram muito presentes, com destaque para preocupações com a gestante, com o bebê, parto, finanças, aumento das responsabilidades e a inexperiência, que se constituem em aspectos do componente de responsabilidade proposto por Lamb et al. (1985).

Após o nascimento, por volta dos três meses do bebê, no seguimento do estudo anterior, Piccinini et al. (2012) revelaram que os 38 pais entrevistados se envolviam nos cuidados do filho, estando disponíveis para eles e para a

1 Embora em português o termo pais refira-se tanto ao pai quanto à mãe, no presente artigo, o termo será empregado apenas para se referir ao genitor masculino, enquanto o termo "pai(s) e mãe(s)" será utilizado para se referir a ambos. mãe do bebê, bem como compartilhando responsabilidades e preocupações com ela, mesmo que em frequência menor. Contudo, nesse período, ressaltaram-se as dificuldades dos pais em desempenhar as atividades de cuidado, refletindo sentimentos de inexperiência e inadequação. Dados semelhantes foram revelados por Saleh e Hilton (2011), em um estudo com 2.512 pais americanos de baixa renda, que mostrou que a interação do pai com o bebê varia ao longo do primeiro ano, sendo que, quanto mais velha a criança, maior o engajamento paterno. A interação do pai com o filho, nesta fase, está mais ligada às brincadeiras (Castoldi, 2002) e ao cuidado compartilhado com a mãe (Silva \& Piccinini, 2007), embora ela seja a referência principal quando se trata de cuidados (McBride \& Mills, 1993).

Em termos de acessibilidade, a literatura revela que os pais que acompanham a esposa durante a gestação e o parto mostram-se mais disponíveis ao longo do primeiro ano do bebê (Shannon, Cabrera, Tamis-LeMonda, \& Lamb, 2009), mesmo que por períodos curtos, devido às extensas horas de trabalho diário (Silva \& Piccinini, 2007). Quanto à dimensão da responsabilidade, ao longo da infância do filho, o pai tende a se manter como responsável pela manutenção da casa e da família em termos financeiros, ainda que a companheira também trabalhe e participe financeiramente (Goetz \& Vieira, 2009).

Os estudos revistos evidenciam que o conceito de envolvimento paterno proposto por Lamb et al. (1985) se constitui em um referencial que permite compreender aspectos da paternidade em diferentes contextos. Entendese que o conceito pode ser também útil para investigar o envolvimento paterno aos 24 meses do filho, fase que se caracteriza pela expansão dos vínculos afetivos, por uma maior autonomia e pela busca da criança em estabelecer sua identidade, tendo como impacto a reorganização da forma como os adultos interagem com ela (Carvalho, Pedrosa, \& Rossetti-Ferreira, 2012). Nesse sentido, o presente estudo teve como objetivo investigar o envolvimento paterno aos 24 meses de vida da criança, com base nas três dimensões do envolvimento paterno propostas por Lamb et al. (1985): interação, disponibilidade e responsabilidade. Este estudo complementa estudos realizados anteriormente com os mesmos participantes que investigaram o envolvimento paterno na gestação (Piccinini et al., 2004) e no terceiro mês do bebê (Piccinini et al., 2012). O conjunto desses estudos permitirá uma melhor compreensão sobre o envolvimento paterno em várias fases do desenvolvimento da criança.

\section{Método}

\section{Participantes}

Participaram deste estudo 27 pais, com idades entre 19 e 40 anos, sendo que a maioria tinha um filho $(63 \%)$; outros, dois $(33,3 \%)$ ou três $(3,7 \%)$ filhos. Quanto ao nível de escolaridade, muitos pais tinha ensino médio completo $(40,8 \%)$, seguido por fundamental incompleto $(26 \%)$, fundamental completo $(22,2 \%)$ e superior completo $(11 \%)$. Todos viviam com a mãe da criança na região metropolitana 
de Porto Alegre. A criança foco do estudo tinha 24 meses de idade, sendo 16 meninos e 11 meninas.

A amostra foi selecionada entre os participantes de um estudo maior, intitulado Estudo Longitudinal de Porto Alegre: Da Gestação à Escola (ELPA; Piccinini, Tudge, Lopes, \& Sperb, 1998-2012)2. Afora os dados sociodemográficos coletados na gestação e atualizados no $24^{\circ}$ mês, o presente estudo considerou apenas dados obtidos no $24^{\circ}$ mês de vida da criança, tendo sido incluídos todos os pais que atendiam aos critérios do estudo e que tinham dados completos disponíveis. O ELPA recebeu aprovação do Comitê de Ética da UFRGS (Resolução ${ }^{\circ}$ 2006596).

\section{Procedimentos e Instrumentos}

Seguindo os procedimentos do Projeto ELPA (Piccinini et al., 1998-2012), os pais foram convidados a participar do estudo ainda durante a gravidez da companheira. Nessa etapa, o casal era informado a respeito dos objetivos do estudo e respondia a Ficha de contato inicial (Grupo de Interação Social, Desenvolvimento e Psicopatologia [GIDEP], 1998a), a qual buscava verificar se a família atendia aos critérios de inclusão. Era então marcado um encontro na residência dos participantes, quando a mãe e o pai assinavam o Termo de consentimento livre e esclarecido (GIDEP, 1998b) e respondiam a Entrevista sobre dados demográficos da família (GIDEP, 1998c), que visava obter informações adicionais sobre os participantes, como idade, escolaridade, estado civil, ocupação, religião e grupo étnico. Após as coletas de dados realizadas na gestação e no $3^{\circ}, 12^{\circ}$ e $18^{\circ}$ mês, as famílias foram novamente contatadas aos 24 meses de vida da criança. Nessa ocasião, o pai respondeu a Entrevista sobre a experiência da paternidade (GIDEP, 1999), cujas respostas foram analisadas para fins do presente estudo. Essa entrevista investigava diversos aspectos da paternidade, como, por exemplo, as impressões do pai em relação ao filho, seu desenvolvimento e temperamento, seus próprios sentimentos e dificuldades enquanto pai, o dia a dia do pai com a criança, que tarefas assumia nos cuidados com ela, tipos de brincadeiras que fazia e as suas percepções sobre a companheira como mãe. A entrevista durava aproximadamente uma hora, era gravada e foi, posteriormente, transcrita.

\section{Resultados}

A análise de conteúdo qualitativa (Bardin, 1977; Laville \& Dionne, 1999) das entrevistas com o pai foi empregada para investigar seu envolvimento aos 24 meses de vida da

2 Este estudo teve por objetivo investigar os aspectos subjetivos e comportamentais das interações pai-mãe-bebê, assim como as atividades diárias da criança em seus contextos habituais, o comportamento social de crianças pré-escolares e sua transição para a escola de ensino fundamental. O estudo iniciou acompanhando 81 gestantes primíparas que não apresentavam intercorrências clínicas. Os maridos ou companheiros, também foram convidados a participar do estudo caso residissem juntos em situação matrimonial. Foram realizadas várias coletas de dados desde a gestação até os oito anos das crianças (gestação, $3^{\circ}, 8^{\circ}, 12^{\circ}, 18^{\circ}, 24^{\circ}$, $30^{\circ}, 36^{\circ}$ mês e $6^{\circ}, 7^{\circ}$ e $8^{\circ}$ ano). criança. Para tanto, utilizou-se uma estrutura de categorias baseadas nas três dimensões do conceito de envolvimento paterno, propostas por Lamb et al. (1985): interação, disponibilidade e responsabilidade. Para cada categoria de análise, foram utilizadas subcategorias baseadas na literatura (Piccinini et al., 2004, 2012) e nos próprios dados, conforme descrito abaixo. Para fins de análise, dois dos autores do presente estudo leram exaustivamente todas as entrevistas e classificaram os relatos dos pais nas categorias de análise. Em caso de discordância, um terceiro autor foi consultado. Apresentam-se a seguir os resultados para cada categoria de análise, ilustrando-as com os relatos dos próprios pais.

\section{Interação com o Bebê}

Nesta categoria, foram incluídos os relatos dos pais a respeito das atividades, de cuidado ou lazer, que realizavam com a criança, compreendendo-se sete subcategorias: brincar, passear, cuidar, conversar, demonstrar afeto, estimular e colocar limites. Quanto ao brincar, a grande maioria dos pais $(96 \%)$ relatou ${ }^{3}$ brincar com seus filhos. Foram citadas tanto brincadeiras mais ativas, como pegar, esconder, lutar e fazer cócegas, como brincadeiras menos ativas, como brincar de boneca, contar histórias, montar e desmontar peças. A partir dos relatos, percebe-se que os pais de meninos, por vezes, descreveram brincadeiras tradicionalmente ligadas ao gênero masculino, como jogar futebol ou brincar de "lutinha": "Eu jogo bastante futebol com ele, ele gosta de jogar futebol. Ás vezes eu chego e ele já pega a bola: 'Vamos jogar bola, jogar gol?"” (P19); enquanto os pais de meninas citaram atividades como brincar de boneca e de panelinha: "Ela pega a boneca e bota no carrinho, e eu embalo" (P25). No que se refere a passear, muitos pais $(26 \%)$ citaram realizar essa atividade com seus filhos, como passear na casa dos avós, na rua e em parques ou praças. Essas subcategorias também se destacaram no momento em que os pais foram perguntados sobre o que mais gostavam de fazer com seus filhos. A maioria dos pais $(51 \%)$ se referira ao brincar como o que mais gostava de fazer, relatando intensa satisfação com a atividade: "Quando a gente brinca, a gente se diverte, eu vejo que ela gosta de brincar, então eu me divirto também. É a parte melhor" (P20); enquanto muitos pais (37\%) mencionaram o passear com a criança como a atividade preferida: "Gosto de sair com ele, gosto de levar ele pra cortar o cabelo. Gosto de sair pra rua. Na pracinha, também levo ele" (P15).

A respeito do cuidar, a grande maioria dos pais $(92 \%)$ relatou envolver-se em atividades cotidianas de cuidado da criança. A atividade mais citada pela maioria dos pais $(62 \%)$ foi dar banho na criança: "Vem vamos tomar banho com o pai!', ai ele larga o que tiver fazendo e vem tomar banho" (P2). Do mesmo modo que o banho, dar comida para a criança também foi uma das atividades mencionada pela maioria dos

3 Para facilitar a exposição dos achados foi utilizada a seguinte descrição quanto ao número de participantes que fizeram relatos classificados em cada categoria: um/alguns pais: 1 a $6(23 \%)$; muitos pais: $7(26 \%)$ a 13 (48\%); a maioria dos pais: $14(52 \%)$ a $20(74 \%)$; a grande maioria/todos os pais: $21(78 \%)$ a $27(100 \%)$. Já a autoria das vinhetas é identificada pela letra ' $\mathrm{P}$ ' seguida do número do caso. Tal classificação foi adaptada com base em Hill, Thompson, Williamns, Hess, e Ladany,(2005). 
pais (62\%): "Ela quer comer com a mão dela direitinho. As vezes eu até digo: 'Deixa, filha. Deixa que o papai dá pra ti!'. Mas ela diz: 'Não, papai! 'Dêssá que eu como!'” (P8). A partir das falas de muitos dos pais, percebe-se que as crianças já conseguiam em certa medida comer sozinhas, embora, por vezes, necessitarem da ajuda do adulto. Outra situação citada pela maioria dos pais (59\%) foi a troca de fralda ou levar a criança até o vaso/penico: "Um dia ela faz tudo nas calças e tem dias que ela não faz. Ela pede: 'xixi', daí eu levo ela no sapinho e ela faz" (P11). Escovar os dentes da criança também foi uma atividade relatada pela maioria dos pais (55\%): “Vamos escovar os dentes, filho?'. 'Vamos'. Ai a gente vai lá: 'Ó, vamos escovar. Para quieto, abre a boca'. Daí ele abre" (P5). Como visto nesses últimos relatos, em função de uma maior autonomia da criança, atividades como dar comida, levar ao banheiro e escovar os dentes da criança já eram parcialmente realizadas por elas, embora precisassem muitas vezes ser auxiliadas ou direcionadas pelos pais.

Além disso, muitos pais (37\%) mencionaram trocar ou colocar roupa na criança como uma das atividades que realizavam, assim como colocar a criança para dormir $(26 \%)$ : “'As vezes, eu digo: 'vamos dormir agora!'. Ai ele vai lá choraminga um pouquinho, ai tu dá uma mamadeirinha para ele e aí daqui a pouco quando vê ele tá estaqueado" (P2); e cuidar da criança quando estava doente (22\%), levando-a ao hospital, por exemplo: "Uma vez só que a gente teve que sair com ele de madrugada, porque ele estava com muita febre. Aí eu peguei e levei ele na emergência" (P15).

Para muitos pais (48\%), várias das atividades que mencionaram eram compartilhadas com a mãe da criança: "Quem tiver perto troca, não tem muito 'Ah isso é tu que faz, isso é eu'. Botar roupa, o banho, isso aí tudo quem tiver com ele faz sem estresse nenhum. Não tem função de um, função de outro" (P24). No entanto, em muitos casos (30\%), o pai relatou situações em que realizava atividades com a solicitação da esposa: "Sempre foi ela [mãe]. Mas uma vez até eu tirei ela [filha] do banho, sequei ela, tudo, mas 99\% é ela quem faz. Eu tô ali, às vezes, auxiliando, mas o principal é ela quem faz" (P11). Já alguns pais (15\%) mencionaram atividades que somente eles fazem, como levar o filho à creche: "Eu espero ela acordar, daí eu mudo, boto roupinha pra levar pra escolinha, boto no carrinho e levo ela no carrinho" (P25).

Quando foram questionados sobre o que menos gostavam de fazer com a criança, alguns pais (15\%) mencionaram a realização de atividades de cuidado: "Levar ele pro banho. Trocar a fralda dele também não gosto, ele se mexe muito" (P15); dois pais relataram não gostar dos momentos em que o filho estava doente: "Tudo que eu sei que ele vai sofrer um pouquinho, eu não gosto de fazer. Então, bah, quando tinha que levar ele na médica, era um suplício para ir" (P19); e ainda um pai mencionou que não gostava de levar a filha para creche: "Que eu menos gosto de fazer? É levar ela pra creche, deixar ela na creche" (P25), em função de vê-la passar por uma situação de sofrimento.

Com relação a conversar com o filho, muitos pais (41\%) relataram que as conversas se tornaram possíveis pelo fato de as crianças já conseguirem se expressar melhor verbalmente: "Quando eu levo ele para a vó, por exemplo, vou conversando com ele. Antes eu só conversava e ele ia lá, olhando para fora. Agora, eu converso com ele, daqui a pouco, ele responde. Então, agora já tá aquela troca" (P19). Entre outras finalidades, as conversas citadas pelos pais tinham a função de acalmar a criança: "Quando ela tá chorando e eu digo para ela parar: 'Não filha, pra que chorar?'Ai, às vezes, ela para e tenta entender o que eu estou falando" (P8); e explicar para a criança o porquê de determinadas ações dos pais: “ $E ́$ que, às vezes, ela tá fazendo alguma coisa na hora do banho, então ela pega a choramingar e quer continuar fazendo aquilo ali. Mas ai tu conversa com ela, ela pega e vai para o banho normal" (P6).

As demonstrações de afeto foram relatadas por muitos pais $(37 \%)$ tanto no sentido de demonstrar explicitamente afeição para o filho: "A minha mãe é muito carinhosa, isso eu acho que puxei dela porque eu tô sempre beijando ele" (P16); como do filho para o pai: "Pai, fazer cafuné'. E fica assim na tua cabeça" (P7). Com relação a estimular a criança, nesta fase, muitos pais (33\%) mencionaram atividades que visavam ao aprendizado do filho, especialmente aquelas que estimulavam a autonomia, como o treino ao banheiro e escovar os dentes: "É muito sistemático tirar a fralda $e$ dizer 'Agora nós vamos fazer xixizinho aqui', porque ele vê. Geralmente quando eu vou no banheiro, ele vai junto. Daí quando chega lá, ele faz os mesmos gestos que eu faço" (P19). Além disso, os pais relataram a estimulação da linguagem e cognição da criança, por exemplo, ensinando a falar corretamente e a contar: "A gente conversa com ele: 'Não é bobó é vovó'. Daí ele olha assim: 'Bobó!', dai a gente: "não é bobó, é vovó!"', a gente repete sempre" (P3); "Eu ensino ele a contar: 'Um, dois, três..." (P14).

Com relação a colocar limites, muitos pais (44\%) mencionaram interações que tinham como finalidade limitar as atividades da criança, como não mexer em determinado objeto, não bater e guardar os brinquedos: “É a questão do limite, assim, às vezes, ele tá fazendo uma coisa que não pode e dai ele continua fazendo mesmo depois do não, mas até a gente dá um grito mais forte às vezes" (P26). Também os pais relataram que, quando a criança não estava fazendo algo que devia ser feito, utilizavam frases de ordem, com tom de voz mais firme, para que ela o obedecesse: "Ontem eu fui botar o chinelo nela e ela queria ir com o chinelo havaianas que a gente comprou pra ela tomar banho. Aí, eu digo: 'Não! Esse não, esse é pra banho!" (P6); ou recorriam ao castigo como uma prática: "É que ele é muito brabo. Eu também sou brabo, então eu engrosso muito com ele. Ele não vai e eu boto ele de castigo" (P9). Colocar limites também foi mencionado por alguns pais $(22 \%)$ quando foram questionados sobre o que menos gostavam de fazer com a criança: "Eu não gosto é de brigar com ele, tipo quando ele tá enchendo o saco e desligando a televisão. Eu não gosto, eu não me sinto legal de xingar ele, de ter que brigar com ele por causa disso" (P12).

\section{Disponibilidade}

Essa categoria compreende os relatos dos pais sobre sua disponibilidade de tempo e atenção para a criança. É composta por duas subcategorias: quantidade de tempo e avaliação do tempo com a criança. 
No que diz respeito à quantidade de tempo com a criança, a maioria dos pais $(51 \%)$ relatou que disponibiliza parte do dia ou da semana para estar junto ao filho: "Quando surge um tempo eu vou em casa almoçar. Daí eu chego lá e todo mundo já almoçou, dai ele come um pouquinho comigo de novo" (P12). Para muitos pais (33\%), o turno que eles têm disponível para estar com a criança é a noite: "A gente diz lá em casa: a [mãe] é a mãe do dia e eu sou a mãe da noite" (P7); e/ou durante os finais de semana (37\%): "Quando eu vou trabalhar fim de semana, ela [filha] fica com a [mãe]. E a tarde eu fico com ela" (P11). Os demais salientaram que dispunham da hora do almoço (dois); de manhã antes de saírem para o trabalho (dois); e/ou no período de férias (um) para fazer companhia ao filho.

Com relação à avaliação do tempo com a criança, a maioria dos pais $(55 \%)$ referiu ter pouco tempo para ficar com ela, o que impedia uma maior participação nos cuidados e na rotina do filho: "O único dia que nós podemos ficar juntos, nós três, é domingo. Quer dizer, são quatro dias num mês. Isso é pouco, pouquíssimo" (P1). Para a grande maioria dos pais $(81 \%)$, a disponibilidade de tempo que o pai tem para estar com a criança apareceu, limitada devido ao trabalho: "Eu trabalho 12, às vezes 13 horas por dia. Tem dias que eu chego só de noite. Aí eu não vejo quase nada dele" (P2). Além disso, o cansaço causado pela rotina intensa de trabalho dificultava o envolvimento de alguns pais (15\%), mesmo quando estes estavam com a família: "Às vezes, tem uma coisa também de chegar cansado e não tá a fim de fazer nada" (P15). Por fim, os estudos (dois pais) ou atividades de esporte/lazer (um) também influenciavam o tempo que ele tinha disponível para ficar com o filho.

Em função do afastamento diário do filho, muitos pais (37\%) relataram sentir saudades e falta da criança: "Ontem foi um dia que eu não vi ele. Fui ver ele hoje de manhã. Quando não vê ele, bate aquela saudade" (P13). Ao mesmo tempo, dois pais afirmaram sentir pena do filho por não poderem ficar com ele: "Às vezes eu saio correndo, ele vê, sai e começa a chorar, ele tenta sair atrás de mim. Aí ele fica chorando, aí eu fico com pena dele, tento voltar, mas não dá. Eu tenho que ir trabalhar" (P14). Apesar de terem avaliado o tempo que dispõem para ficar com a criança como pouco e/ou do sentimento de saudades, apenas um pai (P16) expressou o desejo de ter mais tempo para passar com o filho e alguns pais $(18 \%)$ relataram que tentavam suprir a sua ausência de alguma forma, seja ligando para falar com a criança ou mudando a sua rotina para poder ficar mais tempo com ela: "Eu estava sem nenhuma noite para ficar junto com ele. Ai eu parei com o futebol na quarta para ficar mais com ele. Pelo menos na quarta eu fico a noite toda com ele" (P19).

\section{Responsabilidade}

Essa categoria abrange os relatos dos pais sobre as responsabilidades que assumiam com a criança no que diz respeito à participação e a influência direta na rotina, em aspectos educativos e de cuidado. É composta por cinco subcategorias: aumento das responsabilidades, conversa sobre cuidado/educação, mãe como principal responsável, participação nas decisões e preocupações.
Quanto ao aumento das responsabilidades, muitos pais $(33 \%)$ relataram que a criança tinha prioridade com relação as suas atividades, deixando, por exemplo, momentos de lazer com os amigos ou a companheira em segundo plano: "Só é um pouco complicado porque a gente não pode fazer coisas. Eu e a [mãe], às vezes, a gente quer sair, a gente não vai. É ele em primeiro lugar" (P9). Quanto às conversas sobre o cuidado/ educação da criança, a grande maioria dos pais $(81 \%)$ relatou situações em que ele e a companheira conversaram sobre temas como: práticas educativas (bater, castigar, gritar), início do desfralde, tipo de cuidado alternativo, tipos de comida (doces, carne), entre outros. Em algumas situações, foram relatadas concordância do casal: "A gente não tem essa de um briga e o outro diz: 'Não faz isso!'. A gente tenta atuar juntos. Quando ela não concorda com alguma coisa ela fala pra mim sem ela [filha] ver, porque a gente combinou isso" (P20); bem como discordâncias: "Ela [mãe] faz uma coisa que a guria [filha] quer, dai tem vezes que eu digo: 'Não, não faz, dai ela vai acostumar, vai querer sempre!', mas a [mãe] vai fazer pra ela" (P25).

Com relação às atividades com a criança, a grande maioria dos pais (92\%) mencionou a mãe como principal responsável. A mãe foi citada como responsável pelos cuidados diários, como trocar fralda, dar banho, alimentar: "Se eu tiver em casa e precisar dar banho, eu dou, mas atualmente mais é a [mãe]" (P8); bem como por dar limites para a criança: "Ela [mãe] é mais durona e eu sou o mais mansinho. É ela que briga com ele [filho]. Eu sou mais o protetor e ele vem pro meu colo quando apanha" (P4). Os pais explicaram que essa responsabilidade é atribuída ao fato de a mãe saber o melhor modo de cuidar do filho: "Quase sempre é ela [mãe] que troca a fralda dele [filho]. Eu vou lá ajudo, mas, às vezes, não sei. Ela sempre diz: 'Não, deixa que eu troco direitinho!', ai ela vai lá e troca melhor. Ela sabe fazer melhor" (P3); ou ainda pelo fato de os pais estarem trabalhando ao longo do dia: "Quem tá mais com ela é a mãe dela, porque eu saio pra trabalhar" (P25).

No que se refere à participação nas decisões, a maioria dos pais $(62 \%)$ relatou participar de decisões relacionadas à criança em conjunto com a mãe: "A gente sempre conversa tudo antes. Toma sempre junto as decisões" (P5). A participação nas decisões mencionadas pelos pais diz respeito à escolha do cuidado alternativo, momento de iniciar o desfralde e a criança ir dormir no próprio quarto: "A gente pretende, assim que a [mãe] começar a trabalhar, botar ele [filho] numa creche pra ele ter mais convivência com outras crianças" (P5).

Um dos aspectos incluído na dimensão de responsabilidades são as preocupações dos pais com a criança. No presente estudo, a maioria dos pais (62\%) se mostrou preocupada com a saúde do filho, o que inclui questões relacionadas à criança não ficar doente e ter hábitos saudáveis: "Aí deixa ele sem roupa em cima da cama e pega aquele ventinho. Agora tem esfriado um pouco e eu já me preocupo" (P13); "Então eu falo pra [mãe] pra tomar cuidado, dar fruta, alguma coisa assim pra ela [filha] não ficar sempre comendo coisas que não combinam com ela. Dão muita porcaria e não é saudável" (P18). Também apareceram muitos relatos (26\%) de pais que ficavam junto da criança para evitar que ela se colocasse em situações perigosas e se machucasse: “ $\grave{A}$ 
vezes, a gente tá fazendo alguma coisa que tá meio perigoso e a gente tira ele. Que nem, às vezes, a gente tá na cozinha cortando alguma coisa e ele vem junto para olhar, ai a gente tira ele" (P3). Três pais mencionaram que buscavam transmitir para o filho alguns ensinamentos considerados importantes para a sua saúde e proteção: "Eu falo pra ele: 'Não, isso machuca. Isso corta', 'Não pode fazer isso, não'. Pra ele não se machucar" (P14).

Além disso, a maioria dos pais (59\%) também relatou preocupação com a educação do filho, principalmente no que se refere a este ter uma "boa criação" (26\%), sendo destacada a importância de passar princípios e bons modos para a criança desde pequena: "Eu tento ser o mais correto possível. Tentar mostrar pra ele o que é certo. Tirar o certo do errado e tentar mostrar pra ele o melhor caminho" (P4). Com relação a isso, muitos pais (26\%) mencionaram também estar preocupados com o modo de educar e criar o filho: " $A$ gente não precisa bater numa criança, né. (...) Eu procuro chegar, procurar, conversar" (P6).

Ao mesmo tempo, alguns pais (18\%) também referiram estar preocupados com a socialização da criança: "Eu acho que é bom [ir à creche] pra ela conhecer mais amiguinhos, ter assim uma vida um pouco mais social" (P18); e com o seu desenvolvimento e sua aprendizagem (18\%): "Vamos ver depois que ele estiver lá [na creche] o que ele vai aprender, eu espero que ele progrida lá bastante" (P5). Nesse contexto, a creche foi considerada como um local que atenderia a essas demandas dos pais: "Conviver com outras crianças, viver outras situações longe de pai e de mãe, até pra parte social, eu acho que vai ser importante pra ele" (P24).

Igualmente, a maioria dos pais (74\%) se mostrou preocupada em ser um bom pai. Desse modo, eles relataram que procuravam ser pais exemplares, fazer o melhor possível para a criança, não deixar nada faltar para ela e proporcionar tudo o que ela precisava, como atenção, cuidado e carinho: "Eu procuro fazer o melhor possível aí para manter ela bem" (P21). Para tanto, a maioria dos pais (62\%) referiu possuir algum modelo - geralmente o pai, a mãe ou algum conhecido - que eles buscavam seguir ou evitar na forma de se relacionar com a criança: "Se eu tiver que seguir um exemplo, um pouco de alguém, seria o meu pai. Ojeito firme. O jeito que te ensina, tem princípios próprios, que ele trouxe lá da infância dele que ele passou pra mim" (P11); "O meu pai era uma pessoa, assim, que não passava um carinho, então a gente sempre tem procurado olhar desse lado e não querer passar isso. De passar o carinho, o amor" (P10).

Além disso, a maioria dos pais $(67 \%)$ mencionou ter preocupações quanto aos cuidados fornecidos por outras pessoas (avós, tios, babá e creche): "Preocupado, preocupado com ela. (...) Não sabe como é lá [na creche], não sabe se vão cuidar bem da criança como a gente cuida" (P25). Os pais relataram que essas formas de cuidados possuem algumas características consideradas negativas por eles, o que os deixa preocupados: "Os dois [avós] eles gostam bastante de fazer tudo que não pode, tudo que não deve fazer. (...) Que a vó dela dá Bis, dá refri, dá bala, dá bombom. A vó dela dá tudo que é porcaria" (P18). Apesar disso, a grande maioria dos pais (78\%) avaliou como positivo o cuidado disponibilizado por outras pessoas aos seus filhos: "Elas [avós] cuidam direitinho, dão a alimentação direitinho. (...)
Sempre cuidando ele direitinho pra não se machucar, não cair" (P14).

Por fim, alguns pais (18\%) ainda referiram preocupações com o sustento financeiro da família: "Porque a gente com só um [filho] vê que ele exige tantas coisas, alimentos, frutas, que a gente consegue dar" (P10); e muitos pais (26\%) relataram preocupações com a sobrecarga da esposa com relação ao cuidado dos filhos, ao trabalho e/ou aos estudos: "Ela [mãe] se cansa muito com o serviço dela. Tem vez que ela chega irritada em casa. Eu falo pra ela: 'Vai tomar um banho pra descansar. Só te acalma" (P1); "Eu chego, às vezes, em casa e digo: 'Agora deixa que eu fico com ela [filha]'. Pra poder aliviar um pouquinho, porque o tempo todo ali toma muito dela [mãe]" (P17).

\section{Discussão}

Os resultados do presente estudo sobre o envolvimento paterno com o filho aos 24 meses de vida revelaram que os pais se relacionavam com a criança de acordo com as demandas específicas da idade, período em que a criança se torna mais autônoma em algumas atividades, embora ainda necessite de um envolvimento intenso do pai para cuidá-la e para auxiliá-la na aquisição de suas competências. Nesse sentido, para se compreender o envolvimento paterno com o filho, é importante que se considere também o estágio de desenvolvimento físico e socioemocional em que a criança se encontra e quais são as suas necessidades e capacidades.

Com relação à categoria interação com a criança (Lamb et al., 1985), os pais relataram que se envolviam em atividades de cuidado, realizando tarefas como alimentar, trocar, fazer dormir, entre outras. Acrescenta-se, ainda, a postura do pai em auxiliar a criança a dar conta de suas demandas. Assim, muitos dos momentos de interação voltados para o cuidado eram realizados não somente com a finalidade de cuidar da criança no seu sentido estrito, mas de trazer algum ensinamento por meio do cuidado, como ajudar a dormir no seu próprio quarto, levar ao banheiro e incentivar a comer com a colher. Dessa forma, dar a oportunidade para a criança aprender a cuidar de si é mais uma tarefa que se soma ao cuidar realizado pelo pai nesse momento.

Na verdade, aos 24 meses de idade, a criança já apresenta um conjunto de novas aquisições oriundas da fase de dependência relativa (Winnicott,1963/1983). No período anterior, o bebê tende a viver imerso na relação com a mãe, enquanto o pai participaria indiretamente dessa relação, muitas vezes com a principal função de ser o "cuidador" da díade mãe-bebê, protegendo-a e contribuindo para que a mãe conseguisse dedicar-se inteiramente ao seu bebê (Bowlby, 1958/2006; Winnicott, 1957/1982). Já no período dos 24 meses, a função do pai envolveria a introdução de aspectos de ordem, firmeza nos cuidados, expressão do "não", contribuindo para a adaptação da criança ao mundo externo (Winnicott, 1963/1983). Assim, o pai marca sua presença na vida do filho com suas características paternas e não somente como um substituto da mãe (Fulgencio, 2007). Embora algumas dessas considerações teóricas façam referência a um pai mais tradicional, elas parecem ainda ser retratadas nos relatos dos pais do presente estudo, o que sugere sua 
contemporaneidade e o fato de que o desenvolvimento infantil acaba determinando, pelo menos em parte, as interações e envolvimento paterno.

Mesmo que os cuidados cotidianos sejam mais vinculados à figura materna, em nossa sociedade, estes se tornam cada vez mais aspectos relacionados também à paternidade e são caracterizados como atividades de responsabilidade parental ou coparental e não somente materna ou paterna. No entanto, a literatura revela que mãe e pai desempenham, algumas ou muitas vezes, papeis diferentes no cuidado direto e indireto (passeios, lazer) de suas crianças (Goetz \& Vieira, 2009; Silva \& Tokumaru, 2008), com a mãe disponibilizando mais cuidados básicos, proteção e conforto aos filhos (Cabrera, Tamis-LeMonda, Bradley, \& Lamb, 2000; Silva \& Tokumaru, 2008), e o pai se relacionando sobretudo através de brincadeiras (Silva \& Tokumaru, 2008).

O brincar com o pai, quando ocorre, tende a se destacar por ser rico e proporcionar que a criança explore de maneira livre o seu ambiente, tendendo a ser mais sofisticado se baseado em apego seguro pai-criança (Kasura, 2000). Assim, quando o pai interage com o filho, cuidando-o ou se juntando às suas brincadeiras, ele enriquece o mundo da criança, apresentando novos elementos durante os momentos de interação (Winnicott, 1957/1982) ou, ainda, contribuindo para que o filho alcance seu potencial de desenvolvimento durante as brincadeiras (Kasura, 2000).

Outro aspecto a ser destacado, nesta fase de desenvolvimento da criança, e que apareceu no presente estudo, são as brincadeiras do pai com ênfase em ensinar algo para os filhos, estimulando-os a aprender tarefas, como reconhecer letras, cores e contar números, o que corrobora a literatura (Tamis-LeMonda et al., 2004), que destaca que as brincadeiras entre pai e criança, muitas vezes, estão associadas a uma ênfase nas áreas cognitiva e de linguagem. Contudo, segundo Tamis-LeMonda et al. (2004), para que as brincadeiras tenham esse efeito, o pai precisa apresentar uma relação positiva e sensível com a criança (p. ex., mostrar afeição e empatia pela criança, ter expectativas apropriadas à sua idade, divertir-se com ela) e usar estímulos cognitivos (encorajar a criança a falar sobre os brinquedos, ensinar cores, fazer perguntas).

Os resultados do presente estudo, quando confrontados com aqueles sobre envolvimento paterno no $3^{\circ}$ mês de vida do bebê (Piccinini et al., 2012), que usou basicamente os mesmos casos, revelam que as interações pai-criança, em ambos os momentos, ocorriam por meio dos cuidados e das brincadeiras. Contudo, o conteúdo era, muitas vezes, diferente, sendo determinado pela idade da criança. Por exemplo, aos 3 meses, um dos recursos de interação do pai era distrair o bebê para acalmá-lo ou para tirar o foco de algo, o que não foi citado pelos pais aos 24 meses, quando os pais passaram a usar a conversa ou outras maneiras para colocar limites ou ensinar algo importante para a criança.

Sem dúvida, o desenvolvimento físico e cognitivo da criança é um fator importante para a relação pai-criança, sendo que a qualidade dessa relação se aprimora com as novas capacidades e competências que a criança vai desenvolvendo, entre elas, a de se comunicar (Saleh \& Hilton 2011; Silva \& Piccinini, 2007). Os pais estabelecem relações mais próximas e prazerosas quando as crianças são mais velhas e, portanto, mais responsivas, o que facilita a interação paicriança (Fouts, 2008). No entanto, independente da idade da criança, a participação paterna é essencial para a qualidade da relação, contribuindo para a comunicação pai-filho, para a sincronia na interação e para um tom emocional positivo (Monteiro, Veríssimo, Santos, \& Vaughn, 2008). De fato, a participação e o envolvimento afetivo dos pais com os filhos, podem afetar positivamente o seu desenvolvimento físico e emocional (Flouri \& Buchanan, 2003; Veneziano, 2003).

Contudo, o tempo que os pais do presente estudo tinham disponível para interagir e participar da vida da criança era bastante limitado, principalmente devido ao trabalho. Muitos deles dispunham apenas de um turno durante a semana, geralmente à noite, e os finais de semana para conviver com a criança. Tais achados corroboram a literatura que mostra a elevada carga horária de trabalho como um dos fatores que dificultam uma maior participação dos pais no cotidiano da criança, o que os afasta de um envolvimento ideal (Gabriel \& Dias, 201; Jia, Kotila, Schoppe-Sullivan, \& Dush, 2016). Essa sobrecarga de trabalho faz com que muitos pais acabem levando trabalho para ser realizado em casa, conflituando ainda mais com as demandas de atenção da criança em relação aos seus pais (Fagan, Day, Lamb, \& Cabrera, 2014).

Nesse sentido, os resultados do presente estudo sobre a disponibilidades dos pais para estarem com a criança mostraram-se muito semelhantes àqueles dos 3 meses do bebê (Piccinini et al., 2012). Em ambas as idades, vários pais avaliaram como pouco o tempo que passavam junto à criança, relatando sentimentos de saudades quando estavam separados dela. Aos 24 meses, alguns pais tentavam suprir a ausência do contato com o seu filho ligando para ele ao longo dia ou mudando a sua rotina para ter mais tempo para a criança. Tais resultados podem tanto expressar o desejo dos pais de se envolverem mais na vida dos filhos como podem estar refletindo a crescente cobrança social e/ou da esposa para que o pai se faça mais presente nos cuidados do filho (Seward, Yeatts, \& Zottarelli, 2002; Fagan et al., 2014).

Quanto à categoria responsabilidade, o presente estudo corrobora pesquisas anteriores, principalmente no que diz respeito aos cuidados da criança, sendo a mãe a principal responsável por executar essas tarefas (Cabrera et al., 2000; Tokumaru, Zortea, Howat-Rodrigues, \& Andrade, 2011). Geralmente isso tem sido justificado pelos pais pela demanda de trabalho, mas alguns relataram que acreditavam que a mãe tinha mais habilidade para lidar com a criança. De fato, alguns estudos têm destacado que a responsabilidade pelo cuidado tende a ser mais atribuída à mãe por ser mais associada ao papel materno (Levandowski \& Piccinini, 2006; Piccinini et al., 2004) e não necessariamente pelo fato de o pai ter mais limitação de tempo ou de competência para tanto. Já o estudo de Dessen e Oliveira (2013) revelou que as mães compreendiam que os pais faziam o possível pela criança, embora desejassem um maior envolvimento do mesmo em questões familiares.

Por fim, os relatos dos pais do presente estudo, revelaram diversas preocupações com o bem-estar e o desenvolvimento dos filhos, evidenciando seu envolvimento com eles. Entre as preocupações, a de ser um bom pai também apareceu, o que os remetia às suas próprias experiências infantis com os seus pais, que se faziam presentes no seu modo de ser 
pai e nas suas crenças, o que os levava a ser mais atencioso e afetivo do que seu pai e mãe foram com ele (Gabriel \& Dias, 2011). Além disso, como na gestação (Piccinini et al., 2004) e nos três meses do bebê (Piccinini et al., 2012), os pais se mostraram preocupados com as finanças da casa $\mathrm{o}$ que corrobora a literatura de que os pais ainda tendem a ser os principais responsáveis pelo sustento financeiro, pelo menos no início da infância, quando as mães tendem a diminuir sua atividade remunerada e aumentam suas atividades de cuidado da criança, enquanto o homem tende ao contrário (Goetz \& Vieira, 2009; Yavorsky et al., 2015).

A partir dos resultados do presente estudo, pode-se perceber que as justificativas atribuídas pelos pais para a maior responsabilização da mãe tendem a se manter, pelo menos em parte, ao longo da infância, especialmente ligadas a uma maior proximidade e habilidade da mãe em lidar com o filho. Além disso, cada desafio imposto pelas novas fases de desenvolvimento da criança também pode trazer dificuldades de responsabilização para os pais, mesmo que a interação pai-criança eventualmente possa também melhorar com o tempo (Saleh \& Hilton, 2011).

\section{Considerações Finais}

Os resultados do presente estudo explicitaram as diversas formas de envolvimento do pai com a criança aos 24 meses, muitas delas associadas à fase do desenvolvimento em que a criança se encontrava. Os pais mostravam-se envolvidos ao interagirem com as crianças, bem como estando disponíveis e sendo responsáveis pela criança. Além disso, os resultados indicam que os pais envolviam-se com seus filhos de diferentes formas e com frequência variada, mas a sua participação ainda era percebida como menor do que a da mãe, mesmo quando ele compartilhava dos cuidados e responsabilidades. Aos 24 meses da criança, o pai possuía diversas oportunidades de se envolver com o filho, seja devido seu desenvolvimento emocional, físico e cognitivo, seja pela confiança que ele eventualmente passou a ter nas suas competências paternas para se relacionar com a criança.

Os resultados do presente estudo trazem contribuições teóricas e empíricas frente às questões atuais envolvendo a paternidade, em que a mulher está cada vez mais inserida no mercado de trabalho e o homem acaba sendo chamado a assumir mais tarefas domésticas e a se envolver de maneira mais intensa na vida e na criação dos filhos (Yavorsky et al., 2015). Contudo, como destacaram Yavorsky e colegas, embora a mulher tenha ingressado cada vez mais em atividades tradicionalmente dominadas pelos homens, como no trabalho remunerado e educação superior, os homens não têm se envolvido com a mesma intensidade nas atividades tradicionais das mulheres, entre elas, o cuidado do filho e da casa. Assim, a parentalidade é ainda um domínio em que mulheres e homens experienciam responsabilidades desiguais.

Nesse sentido, os achados do estudo podem ser empregados para embasar intervenções junto às famílias, em ações voltadas para a promoção de um maior envolvimento paterno na vida do filho, o que trará contribuições não só para o filho como para a própria experiência da paternidade.
Contudo, os resultados encontrados estão limitados pelo contexto específico dos participantes dessa pesquisa, os quais moravam junto com a mãe e os filhos em um grande centro urbano. Nesse sentido, recomenda-se a realização de outros estudos que investiguem não só o envolvimento paterno em diferentes etapas do desenvolvimento infantil, inclusive para além dos 24 meses da criança, como também em diferentes contextos e em distintas configurações familiares, o que permitirá examinar a extensão com que os resultados aqui encontrados se fazem presentes em outros contextos. E, para além do envolvimento paterno, é importante que se ampliem as investigações incluindo também os aspectos subjetivos associados ao envolvimento e à própria paternidade.

\section{Referências}

Bardin, L. (1977). Análise de conteúdo. Lisboa: Edições70.

Bowlby, J. (2006). Psicanálise e cuidados com a criança. In J. Bowlby, Formação e rompimento dos laços afetivos ( $4^{\mathrm{a}} \mathrm{ed}$., pp. 13-41). São Paulo: Martins Fontes. (Original published in 1958)

Brown, G. L., Mangelsdorf, S. C., \& Neff, C. (2012). Father involvement, paternal sensitivity, and father-child attachment security in the first 3 years. Journal of Family Psychology, 26(3), 421-430.

Cabrera, N. J., Tamis-LeMonda, C. S., Bradley, R. H., \& Lamb, M. E. (2000). Fatherhood in the twenty-first century. Child Development, 71(1), 127-136.

Castoldi, L. (2002). A construção da paternidade desde a gestação até o primeiro ano do bebê (Dissertação de mestrado não publicada). Universidade Federal do Rio Grande do Sul, Porto Alegre, RS, Brasil.

Castoldi, L., Gonçalves, T. R., \& Lopes, R. C. S. (2014). Envolvimento paterno da gestação ao primeiro ano de vida do bebê. Psicologia em Estudo (Maringá), 19(2), 247-259. doi: http://dx.doi.org/10.1590/1413-737222105008

Carvalho, A. M. A., Pedrosa, M. I., \& Rossetti-Ferreira, M. C. (2012). Aprendendo com a criança de zero a seis anos. São Paulo: Cortez.

Dessen, M. A., \& Oliveira, M. R. (2013). Envolvimento paterno durante o nascimento dos filhos: Pai "real" e "ideal" na perspectiva materna. Psicologia: Reflexão e Crítica, 26(1), 184-192. doi: https://dx.doi.org/10.1590/S010279722013000100020

Fagan, J., Day, R., Lamb, M. E., \& Cabrera, N. J. (2014). Should researchers conceptualize differently the dimensions of parenting for fathers and mothers? Journal of Family Theory \& Review, 6(4), 390-405. doi: DOI10.1111/jftr.12044

Flouri, E., \& Buchanan, A. (2003). The role of father involvement in children's later mental health. Journal of Adolescence, 26(1), 63-78.

Fouts, H. N. (2008). Father involvement with young children among the Aka and Bofi foragers. Cross-Cultural Research, 42(3), 290-312.

Fuertes, M., Faria, A., Breeghly, M., \& Santos, P. L. (2016). The effects of parental sensitivity and involvement in caregiving on mother-infant and father-infant attachment in a portuguese sample. Journal of Family Psychology, 30(1),147-56. doi: 10.1037/fam0000139. 
Fulgencio, C. D. R. (2007). A presença do pai no processo de amadurecimento: Um estudo sobre D. W. Winnicott (Dissertação de mestrado não publicada). Pontifícia Universidade Católica de São Paulo, São Paulo, SP, Brasil.

Gabriel, M. R., \& Dias, A. C. G. (2011). Percepções sobre a paternidade: Descrevendo a si mesmo e o próprio pai como pai. Estudos de Psicologia, 16(3), 253-261.

Goetz, E. R., \& Vieira, M. L. (2009). Percepções dos filhos sobre aspectos reais e ideais do cuidado parental. Estudos de Psicologia, 26(2), 195-293.

Grupo de Interação Social, Desenvolvimento e Psicopatologia. (1998a). Ficha de contato inicial (Instrumento não publicado). Instituto de Psicologia, Universidade Federal do Rio Grande do Sul, Porto Alegre, RS, Brasil.

Grupo de Interação Social, Desenvolvimento e Psicopatologia. (1998b). Termo de consentimento livre e esclarecido (Instrumento não publicado). Instituto de Psicologia, Universidade Federal do Rio Grande do Sul, Porto Alegre, RS, Brasil.

Grupo de Interação Social, Desenvolvimento e Psicopatologia. (1998c). Entrevista sobre dados demográficos da família (Instrumento não publicado). Instituto de Psicologia, Universidade Federal do Rio Grande do Sul, Porto Alegre, RS, Brasil.

Grupo de Interação Social, Desenvolvimento e Psicopatologia. (1999). Entrevista sobre a experiência da paternidade (Instrumento não publicado). Instituto de Psicologia, Universidade Federal do Rio Grande do Sul, Porto Alegre, RS, Brasil.

Henn, C. G., \& Piccinini, C. A. (2010). A experiência da paternidade e o envolvimento paterno no contexto da Síndrome de Down. Psicologia: Teoria e Pesquisa, 26(4), 623-631.

Hill, C. E., Knox, S., Thompson, B. J., Williamns, E. N., Hess, S. A., \& Ladany, N. (2005). Consensual Qualitative Research: An Update. Journal of Counseling Psychology, 52(2), 1-27. doi: 10.1037\%2F0022-0167.52.2.196.

Hohmann-Marriott, B. (2011). Coparenting and father involvement in married and unmarried coresident couples. Journal of Marriage and Family, 73, 296-309. doi: 10.1111/j.17413737.2010.00805.x

Houzel, D. (2004). As implicações da parentalidade. In L. SolisPonton (Ed.), Ser pai, ser mãe: Parentalidade, um desafio para o terceiro milênio (pp. 47-52). São Paulo: Casa do Psicólogo.

Kasura, K. (2000). Fathers' qualitative e quantitative involvement: An investigation of attachment, play and social interactions. The Journal of Men's Studies, 9, 41-57.

Jia, R., Kotila, L. E., Schoppe-Sullivan, S. J., \& Dush, C. M. K. (2016). New parents' psychological adjustment and trajectories of early parental involvement. Journal of Marriage and Family, 78(1), 197-211. doi: 10.1111/jomf.12263

Lamb, M. E., Pleck, J. H., Charnov, E. L., \& Levine, J. A. (1985). Paternal behavior in humans. American Zoologist, 25(3), 883-894.

Laville, C., \& Dione, J. (1999). A construção do saber: Manual de metodologia da pesquisa em ciências humanas. Porto Alegre: Artes Médicas.

Levandowski, D. C., \& Piccinini, C. A. (2006). Expectativas e sentimentos em relação à paternidade entre adolescentes e adultos. Psicologia: Teoria e Pesquisa, 22(1), 17-28.
Manfroi, E. C., Macarini, S. M., \& Vieira, M. L. (2011). Comportamento parental e o papel do pai no desenvolvimento infantil. Revista Brasileira de Crescimento e Desenvolvimento Humano, 21(1), 59-69.

Matthey, S., \& Barnett, B. (1999). Parent-infant classes in the early postpartum period: Need and participation by fathers and mothers. Infant Mental Health Journal, 20(3), 278-290.

McBride, B. A., \& Mills, G. (1993). A comparison of mother and father involvement with their preschool age children. Early Childhood Research Quarterly, 8, 457-477.

Monteiro, L., Veríssimo, M., Santos, A. J., \& Vaughn, B. E. (2008). Envolvimento paterno e organização dos comportamentos de base segura das crianças em famílias portuguesas. Análise Psicológica, 3(26), 395-409.

Piccinini, C. A., Silva, M. R., Gonçalves, T. R., Lopes, R. C. S. L., \& Tudge, J. (2004). O envolvimento paterno durante a gestação. Psicologia: Reflexão e Crítica, 17(3), 303-314.

Piccinini, C. A., Silva, M. R., Gonçalves, T. R., Lopes, R. C. S. L., \& Tudge, J. (2012). Envolvimento paterno aos três meses de vida do bebê. Psicologia: Teoria e Pesquisa, 28(3), 303-314.

Piccinini, C. A., Tudge, J., Lopes, R. C. S., \& Sperb, T. (1998). Estudo longitudinal de porto alegre: Da gestação à escola. Instituto de Psicologia (Projeto de pesquisa não publicado). Instituto de Psicologia, Universidade Federal do Rio Grande do Sul, Porto Alegre, RS, Brasil.

Saleh, M. F., \& Hilton, J. M. (2011). A comparison of the paternal involvement of low-income fathers in four development stages: Adolescence, young adult, adult, and midlife. The Familý Journal, 19(1), 47-55. doi: https://doi. org/10.1177/1066480710387496

Seward, R. R., Yeatts, D. E., \& Zottarelli, L. K. (2002). Parental leave and father involvement in child care: Sweden and the United States. Journal of Comparative Family Studies, 33(3), 387-399.

Shannon, J. D., Cabrera, N. J., Tamis-LeMonda, C., \& Lamb, M. E. (2009). Who stays and who leaves? Father accessibility across children's first 5 years. Parenting: Science and Practice, 9(1), 78-100.

Silva, M. R., \& Piccinini, C. A. (2004). O Envolvimento Paterno em Pais Não-residentes: Algumas Questões Teóricas. Psico (PUCRS), 35(2), 185-194.

Silva, M. R., \& Piccinini, C. A. (2007). Sentimentos sobre paternidade e o envolvimento paterno: Um estudo qualitativo. Estudos de Psicologia, 24(4), 561-573.

Silva, M. R., \& Piccinini, C. A. (2009). Paternidade no contexto da depressão pós-parto materna: Revisando a literatura. Estudos de Psicologia, 14(1), 5-12.

Silva, L. W., \& Tokumaru, R. (2008). Cuidados parentais e aloparentais recebidos por crianças de escolas públicas e particulares de Vitória - ES. Psicologia: Reflexão e Crítica, 21(1), 133-141.

Souza, C. L. C. (2008). Paternidade e desemprego: Características do envolvimento paterno e aspectos do relacionamento familiar (Dissertação de mestrado não publicada). Universidade do Vale do Rio dos Sinos, São Leopoldo, RS, Brasil.

Tamis-LeMonda, C. S, Shannon, J. D., Cabrera, N. J., \& Lamb, M. E. (2004). Fathers and mothers at play with their 2- and 3-yearolds: Contributions to language and cognitive development. Child Development, 75(6), 1806-1820. 
Tokumaru, R. S., Zortea, T. C., Howat-Rodrigues, A. B. C., \& Andrade, A. L. (2011). Diferenças no investimento materno em função de variáveis socioambientais. Estudos de Psicologia, 16(1), 49-55.

Tudge, J. R. H. (2008). The everyday lives of young children: Culture, class, and child rearing in diverse societies. New York: Cambridge University Press.

Veneziano, R. A. (2003). The importance of paternal warmth. CrossCultural Research, 37(3), 265-281.

Winnicott, D. W. (1982). E o pai?. In D. W. Winnicott, A criança e o seu mundo (pp. 127-133). Rio de Janeiro: LTC Editora. (Original published in 1957)
Winnicott, D. W. (1983). Da dependência à independência no desenvolvimento do indivíduo. In D. W. Winnicott. O ambiente e os processos de maturação. Porto Alegre: Artes Médicas. (Original publicado em 1963)

Yavorsky, J. E., Dush, C. M. K., \& Schoppe-Sullivan, S. J. (2015). The production of inequality: The gender division of labor across the transition to parenthood. Journal of Marriage and Family, 77(3), 662-679. doi: 10.1111/jomf.12189

Yoshihara, C. (2008). Qualidade de vida e envolvimento paterno em crianças e adolescentes com transtorno do desenvolvimento (Dissertação de Mestrado não publicada). Universidade Federal de Minas Gerais, Belo Horizonte, MG, Brasil. 